\title{
A DOUBLE-BLIND COMPARISON OF CARBONATED LIDOCAINE AND LIDOCAINE HYDROCHLORIDE IN EPIDURAL ANAESTHESIA
}

\author{
D.H. MORISON
}

\begin{abstract}
Twenty patients having a standard epidural anaesthetic were randomly assigned to receive $20 \mathrm{ml}$ of either carbonated lidocaine 1.73 per cent or lidocaine hydrochloride 2.0 per cent, containing epinephrine 1:200,000. An observer unaware of the solution used measured speed of onset, quality of block, and duration of action. No significant difference was demonstrated in the speed of onset or duration of the block. Carbonated lidocaine gave an improved motor block and showed a trend towards giving fewer missed segments than lidocaine hydrochloride.
\end{abstract}

Key Words: Anaesthetic Techniques, Regional, Epidural; ANAESTHETICS, Local, carbonated lidocaine.

Carbonated lidocaine is reported to be an improvement over lidocaine hydrochloride with regard to speed of onset and quality of block when used in epidural anaesthesia. ${ }^{1,2}$ The objectives of this study were to compare the carbonated and hydrochloride preparations of lidocaine in epidural block with respect to speed of onset and quality of block achieved. Previous studies of carbonated lidocaine have not utilized a doubleblind design and thus were open to observer bias. In this study, both the patient and anaesthetist/ observer were blinded as to the solution used.

\section{METHODS}

Twenty patients scheduled for lower abdominal or lower limb surgery, after giving informed consent, received an epidural block administered by one anaesthetist. The patients were randomly assigned to two groups receiving either $20 \mathrm{ml}$ of carbonated lidocaine 1.73 per cent (equivalent to lidocaine hydrochloride 2 per cent) or $20 \mathrm{ml}$ of lidocaine hydrochloride two per cent. Both solutions contained freshly added epinephrine to a concentration of 1:200,000 and were injected over approximately 45 seconds through a Tuohy needle positioned in the second lumbar epidural space as identified by a loss of resistance technique. The patient was immediately turned from a lateral to the supine position and the following measurements were made by an observer unaware of which solution had been used:

D.H. Morison, M.B., Ch.B., F.R.C.P.(C), Associate Professor, Department of Anaesthesia, McMaster University, 1200 Main Street West, Hamilton, Ontario, L8N 325 .

Canad. Anaesth. Soc. J., vol. 28, no. 4, July 1981 (a) The upper level of sensory analgesia as determined bilaterally by the loss of sensation of sharpness to a pin-prick.

(b) The degree of motor block in the lower limbs using a score described by Bromage. ${ }^{3}$ Both of these were measured at one minute intervals for 10 minutes, then every two minutes for a further 10 minutes.

(c) After 20 minutes, the upper level of anaesthesia, defined as the loss of sensation to pinprick, and the presence of missed sensory segments, defined as any area below the upper level of analgesia where pin-prick could be felt.

(d) Blood pressure and pulse rate were recorded every two minutes for 20 minutes using a Dinamap 845 automatic recorder.

(e) Regression of the sensory and motor block were measured at the end of surgery (defined as regression of four sensory segments and disappearance of the motor block).

The sample size was calculated on the basis of the time of onset for maximum analgesia. Using a standard deviation of 2.6 minutes, ${ }^{2}$ a sample size of 10 per group would detect a clinically signifcant difference between groups of three minutes with an $\alpha$ error of 0.5 and a $\beta$ error of 0.1 . Statistical comparisons were done using the independent ' $t$ ' test for continuous data, and the Fischer exact test for ordinal data. A level of $p<$ 0.05 was considered to be significant.

\section{Results}

Table I indicates that the two groups were similar in age, height, weight and sex distribu- 
TABLE 1

\begin{tabular}{lccccc}
\hline \hline & $\begin{array}{c}\text { Age } \\
(\mathrm{yr})\end{array}$ & $\begin{array}{c}\text { Height } \\
(\mathrm{cm})\end{array}$ & $\begin{array}{c}\text { Weight } \\
(\mathrm{kg})\end{array}$ & Male & Female \\
\hline $\mathrm{CO}_{2}$ & $33.1 \pm 3.0$ & $169.6 \pm 2.6$ & $70.8 \pm 4.1$ & 6 & 4 \\
$\mathrm{HCl}$ & $32.5 \pm 2.9$ & $171.7 \pm 2.8$ & $68.2 \pm 4.1$ & 6 & 4 \\
$\mathrm{P}$ & 0.88 & 0.59 & 0.66 & & \\
\hline
\end{tabular}

Age, height, weight, and sex distribution of the two groups expressed as mean \pm SEM.

$\mathrm{CO}_{2}=$ carbonated lidocaine.

$\mathrm{HCl}=$ lidocaine hydrochloride.

TABLE II

\begin{tabular}{lcccccc}
\hline & & \multicolumn{2}{c}{ Onset of Block } & & \multicolumn{2}{c}{ Duration of Block } \\
\cline { 3 - 4 } & Initial Onset & $\begin{array}{c}\text { Maximum Spread } \\
\text { of Analgesia }\end{array}$ & $\begin{array}{c}\text { Maximum Motor } \\
\text { Block }\end{array}$ & & Sensory & Motor \\
\hline $\mathrm{CO}_{2}$ & $4.3 \pm 0.45$ & $13.6 \pm 1.76$ & $12.4 \pm 1.76$ & & $157 \pm 10$ & $157 \pm 10$ \\
$\mathrm{HCl}$ & $4.6 \pm 0.31$ & $11.6 \pm 0.92$ & $11.9 \pm 1.9$ & & $150 \pm 13$ & $141 \pm 9$ \\
$\mathrm{P}$ & 0.59 & 0.2 & 0.83 & & 0.68 & 0.25 \\
\hline
\end{tabular}

Onset of and duration in minutes of the epidural block expressed as mean \pm SEM.

$\mathrm{CO}_{2}=$ carbonated lidocaine.

$\mathrm{HCl}=$ lidocaine hydrochloride.

TABLE III

\begin{tabular}{lccccccr}
\hline & \multicolumn{2}{c}{ Height of Block } & & \multicolumn{2}{c}{ Patients with } & \multicolumn{2}{c}{ Motor Block Score } \\
\cline { 2 - 4 } & Analgesia & Anaesthesia & Missed Segments & 0 & 1 & 2 \\
\hline $\mathrm{CO}_{2}$ & $\mathrm{~T}_{10} \pm 1.14$ & $\mathrm{~T}_{12} \pm 0.76$ & 4 & 1 & 4 & 5 \\
$\mathrm{HCl}$ & $\mathrm{T}_{9} \pm 1.71$ & $\mathrm{~T}_{11} \pm 1.04$ & 7 & 2 & 8 & 0 \\
$\mathrm{P}$ & 0.34 & 0.43 & 0.37 & & $\mathrm{p}=0.044^{*}$ \\
\hline
\end{tabular}

Height of sensory block expressed as mean level \pm SEM, number of patients with missed segments and motor block score achieved.

*Using 2 tailed $2 \times 3$ Fischer exact test (statistically significant).

$\mathrm{CO}_{2}=$ carbonated lidocaine.

$\mathrm{HCl}=$ lidocaine hydrochloride.

tion. Table II shows the mean time for first appearance of analgesia (initial onset), maximum spread of analgesia, maximum spread of motor block, and duration of sensory and motor blocks. No significant differences were demonstrated. The mean onset time for maximum spread of analgesia was 13.6 minutes for carbonated lidocaine and 11.6 minutes for lidocaine hydrochloride.

Table III shows the quality of block achieved as defined by the height of sensory block, degree of motor block, and number of patients with missed segments. The only statistically significant difference was for the degree of motor block where carbonated lidocaine gave a greater degree of motor block than lidocaine hydrochloride ( $p=$ 0.044). There was also a trend towards a clinically significant difference in missed segments; four of the carbonated group and seven of the hydrochloride group had missed sensory segments. The changes in arterial pressure and heart rate were similar in each group and there was no significant difference between them. Neither the systolic or diastolic blood pressure showed any appreciable change, but in both groups the pulse rate increased by approximately 10 beats per minute, six minutes after injection of the local anaesthetic.

\section{Discussion}

Carbonated lidocaine has previously been reported to have a faster onset of action and to give an improved block as compared with lidocaine hydrochloride ${ }^{1,2}$ Bromage reported the time to maximum analgesia for carbonated lidocaine to be 10.6 minutes, approximately 30 per cent faster than for lidocaine hydrochloride. The present 
study does not confirm this finding and no statistically significant difference was demonstrated in the onset time for analgesia. These previous studies did not utilize double-blind designs and may have been affected by observer bias. This important source of potential error was avoided in the present study by the use of a double-blind design. In this study, only 10 patients in each group were investigated. This sample size should have been sufficient to demonstrate a clinically significant difference, had this in fact existed, using the standard deviations found in this study.

The only significant difference found between the two preparations of lidocaine was in the degree of motor block and this agrees with previous reports. ${ }^{1.2}$ A trend towards a lower incidence of missed segments with carbonated lidocaine was also demonstrated in the present study, which might have proved significant if a larger sample size had been employed. ${ }^{4}$ Apart from these two exceptions, no difference was demonstrated between the two preparations of lidocaine in the parameters measured.

The failure to show a difference in speed of onset between carbonated lidocaine and the hydrochloride salt is consistent with the findings of a previous study comparing carbonated bupivacaine and bupivacaine hydrochloride in epidural block. ${ }^{5}$ Carbonation of local anaesthetics does speed the onset of action in the isolated nerve preparation. ${ }^{6}$ The action of local anaesthetics in the epidural space is not analogous, though, to an isolated nerve preparation. Bromage postulates that local anaesthetics placed in the epidural space act at several sites after passing through different diffusion pathways. ${ }^{1}$ Thus the advantage of carbonation of a local anaesthetic may be lost before reaching the principle sites of action when placed in the epidural space.

A clinical situation which may closer resemble the isolated nerve preparation is major nerve blockade, such as brachial plexus block. In fact, carbonated bupivacaine used in brachial plexus block has been shown to be faster in onset than bupivacaine hydrochloride. ${ }^{7}$ In a study ${ }^{8}$ which did not use a double-blind format, the speed of onset with carbonated lidocaine, compared to lidocaine hydrochloride, was reported to be even faster in brachial plexus block than in epidural block. It would, therefore, appear worth comparing the action of carbonated lidocaine and lidocaine hydrochloride in brachial plexus block in a study using a double-blind format.

\section{ACKNOWLEDGEMENTS}

The author wishes to thank Dr. B.G. Covino, Department of Anesthesia, Harvard Medical School, Boston, Massachusetts, and Dr. D.B. Scott, Department of Anaesthetics, The Royal Infirmary, Edinburgh, Scotland, for their advice, encouragement, and criticism of the study; Dr. G.L. Dunn, Department of Anaesthesia, McMaster University, Hamilton, Ontario, Canada for help in the preparation of the paper; Professor R. Milner, who provided statistical advice; and Ms. $\mathrm{S}$. Seaman for the manuscript preparation.

\section{REFERENCES}

I. Bromage, P.R. Epidural Analgesia, 1st ed. Philadelphia: Saunders (1978). Pages 82-84, and 315-318.

2. Bromage, P.R., Burfort, M.F., Crowell, D.E. \& Truant, A.P. Quality of epidural blockade III. Carbonated local anesthetic solutions. $\mathrm{Br}$. J. Anaesth. 39: 197 (1967).

3. Bromage, P.R., Burfort, M.F., Crowell, D.E. \& PetTIgRew, R.T. Quality of epidural blockade I. Influence of physical factors. Br. J. Anaesth. 36: 342 (1964)

4. Bromage, P.R. Unblocked segments in epidural analgesia for relief of pain in labour. $\mathrm{Br}$. J. Anaesth. 44: 676 (1972).

5. Brown, D.T., Morison, D.H., Covino, B.G. \& Scorr, D.B. Comparison of carbonated bupivacaine and bupivacaine hydrochloride for extradural anaesthesia. Br. J. Anaesth. 52: 419 (1980).

6. CAtchlove, R.F.H. The influence of $\mathrm{CO}_{2}$ and $\mathrm{pH}$ on local anaesthetic action. J. Pharm. Exp. Therap. 181: 298 (1972)

7. ScotT, D.B. Br. J. Anaesth. (in press).

8. Schulte-Steinberg, O., Hartsmith, J. \& Sснӥтt, L. Carbon dioxide salts of lignocaine in brachial plexus. Anaes. 25: 19] (1970).

\section{RÉSUMÉ}

On a administré $20 \mathrm{ml}$ de lidocaïne à 1.73 pour cent carbonatée ou $20 \mathrm{ml}$ de lidocaïne à 2 pour cent (avec épinéphrine à 1:200,000 dans les 2 cas) à deux groupes de patients opérés sous anesthésie épidurale. La sélection des malades était faite au hasard dans le cadre d'une étude à double insu. Un observateur non au courant de la solution utilisée notait la vitesse d'installation du bloc, sa qualité et sa durée. On n'a pas trouvé de différence significative dans la vitesse d'installation du bloc et dans sa durée. Cependant la lidocaïne carbonatée donnait de meilleurs blocs moteurs et un bloc sensitif plus homogène (moins de segments manqués). 